\title{
PENGARUH MODEL DIFRAKSI TERHADAP PERAMBATAN GELOMBANG DETONASI PADA CAMPURAN BAHAN BAKAR HIDROGEN-OKSIGEN DENGAN DILUENT ARGON
}

\author{
Bambang Puguh \\ Jurusan Teknik Konversi Energi - Politeknik Negeri Bandung \\ Email: bambang.energi@gmail.com
}

\begin{abstract}
Abstrak
Pada sistem pembakaran supersonik, shock wave dan reaction wave merambat dengan kondisi berhimpit dengan kecepatan di bawah 1 mikro detik. Shock wave yang memiliki tekanan tinggi hingga mencapai 20 kali tekanan awal akan membahayakan bagi keselamatan manusia jika kecelakaan detonasi terjadi. Dengan demikiaan diharapkan kecelakaan yang diakibatkan oleh gelombang detonasi akan dapat dihindari atau diminimalisasi. Hal ini dilakukan dengan cara mengubah gelombang detonasi menjadi gelombang deflagrasi, yaitu memisahkan shock wave dengan reaction wave akibat proses ekspansi gelombang detonasi. Pada eksperimen ini, model diuji pada pipa uji detonasi (PUD) horizontal berpenampang lingkaran dengan diameter dalam $50 \mathrm{~mm}$ dan panjang $6.300 \mathrm{~mm}$ yang terdiri dari seksi driver sepanjang $1000 \mathrm{~mm}$, seksi driven sepanjang $5300 \mathrm{~mm}$. Pada seksi driven dipasang model facing step 50 $\%$ dengan bahan alumunium sepanjang $300 \mathrm{~mm}$. Empat unit sensor tekanan yang berfungsi untuk merekam profil tekanan sepanjang proses pembakaran dan empat unit ionisation probe yang berfungsi untuk mendeteksi waktu kedatangan flame front, dipasang masing masing 2 unit di upstream dan 2 unit di downstream dari model dengan posisi saling berhadapan. Campuran bahan bakar untuk seksi driver yang digunakan pada experimen ini adalah campuran hidrogen dan oksigen dengan kondisi stokiometrik dan tekanan awal $100 \mathrm{kPa}$ untuk menjamin terjadinya detonasi pada seksi driver, sedangkan pada seksi driven campuran bahan bakar yang digunakan adalah campuran hidrogen-oksigen dengan diluent argon pada variasi tekanan awal mulai $20 \mathrm{kPa}$ hingga $100 \mathrm{kPa}$. Dari hasil penelitian diperoleh 3 mekanisme perambatan gelombang detonasi di belakang model facing step $50 \%$, yaitu a) Reinisiasi detonasi oleh adanya DDT, yaitu kondisi merambatnya kembali gelombang detonasi akibat proses deflagration to detonation transition di daerah downstream dari model setelah sebelumnya quenching detonasi akibat gelombang ekspansi, (b) Reinisiasi detonasi oleh adanya $S$-W, kondisi merambatnya kembali gelombang detonasi akibat adanya interaksi gelombang kejut dengan dinding pipa, (c) transmisi detonasi, merupakan proses perambatan gelombang detonasi tanpa melalu proses quenching di daerah downstream dari model.
\end{abstract}

Kata kunci : detonasi, deflagrasi, shock wave, facing step.

\section{PENDAHULUAN}

\section{Latar Belakang}

Detonasi adalah gelombang pembakaran yang merambat pada kecepatan supersonic, dimana shock wave akan terbentuk tepat di depan reaction wave. Semakin cepat reaction rate, maka shock wave akan semakin dekat dengan reaction wave sehingga keduanya meranbat berhimpit dengan jarak di tawah $1 \mu \mathrm{s}$, dan pada kondisi ini terjadi detonasi. Fenomena detonasi ini memiliki tekanan yang sangat tinggi hingga bisa mencapai lebih dari 20 kali dari tekanan awal. Tekanan yang ekstrim tinggi ini berpotensi membahayakan keselamatan manusia dan dapat menghancurkan peralatan yang ada.

Untuk menghindari kecelakaan yang terjadi karena detonasi, maka pada sistem yang menggunakan bakan bakar yang sangat reaktif memerlukan alat pengaman yang berfungsi untuk menghentikan proses perambatan detonasi. Cara mengendalikan detonasi ini hanya efektif jika perambatan shock wave dan reaction wave dapat dipisahkan. Salah satu teknik untuk mengendalikan perambatan detonasi adalah dengan menghambat laju gelombang detonasi. Cara inilah yang dipergunakan untuk mendesain alat pengaman detonasi (detonation arrester) yang keberadaannya dapat memberikan rasa aman di industri atau suatu sistem yang menggunakan pipa sebagai media untuk mengalirkan bahan bakar murni ataupun premixed untuk menunjang proses kerjanya.

Penelitian ini bertujuan untuk mengetahui karakteristik dan pola perambatan detonasi di belakang model facing step yang dapat digunakan sebagai metode dalam mendesain alat pengaman di industri yang menggunakan 
bahan bakar hidrogen dengan diluent argon, sehingga jaminan keamanan dapat terpenuhi.

Dari penelitian ini diharapkan dapat diketahui mekanisme dan pola rambatan detonasi di belakang model facing step $50 \%$ serta parameter-parameter apa saja yang mempengaruhi perambatan detonasi sehingga didapatkan data yang akurat untuk mendesain detonation arrester pada suatu sistem yang menggunakan bahan bakar hidrogen.

\section{Tinjauan pustaka}

Quenching detonasi dapat tercapai jika perambatan gelombang detonasi mengalami fenomena difraksi yang melalui perubahan diameter pipa. Gelombang detonasi yang melalui suddent enlargement akan mengalami perubahan kecepatan, sehingga gelombang detonasi dapat dikendalikan menjadi deflagrasi.

Ohyagi et al. (2002) melakukan penelitian difraksi dan re-inisiasi detonasi melalui backward-facing step yang menyimpulkan bahwa penghalusan gelombang yang dipancarkan dari sudut difraksi dapat mengurangi kekuatan shock wave, dimana semakin kecil tekanan awal bahan bakar mengakibatkan terjadinya kegagalan detonasi di belakang model.

Sedangkan berkaitan dengan unjuk kerja bahan bakar, Sentanuhady (2006) melakukan eksperimen menggunakan campuran bahan bakar gas hidrogen, udara dan argon. Hasil penelitian menunjukan bahwa detonasi akan merambat dengan mudah jika campuran bahan bakar hidrogen udara dan argon sekitar 1,3.

Pada tahun 2007, Zhu et al. meneliti menggunakan perforate plate sebagai pembangkit difraksi pada gelombang detonasi, menyimpulkan bahwa batas kritis terjadinya detonasi yang disebut $\mathrm{CJ}$ deflagrasi merupakan setengah kecepatan CJ detonasi .

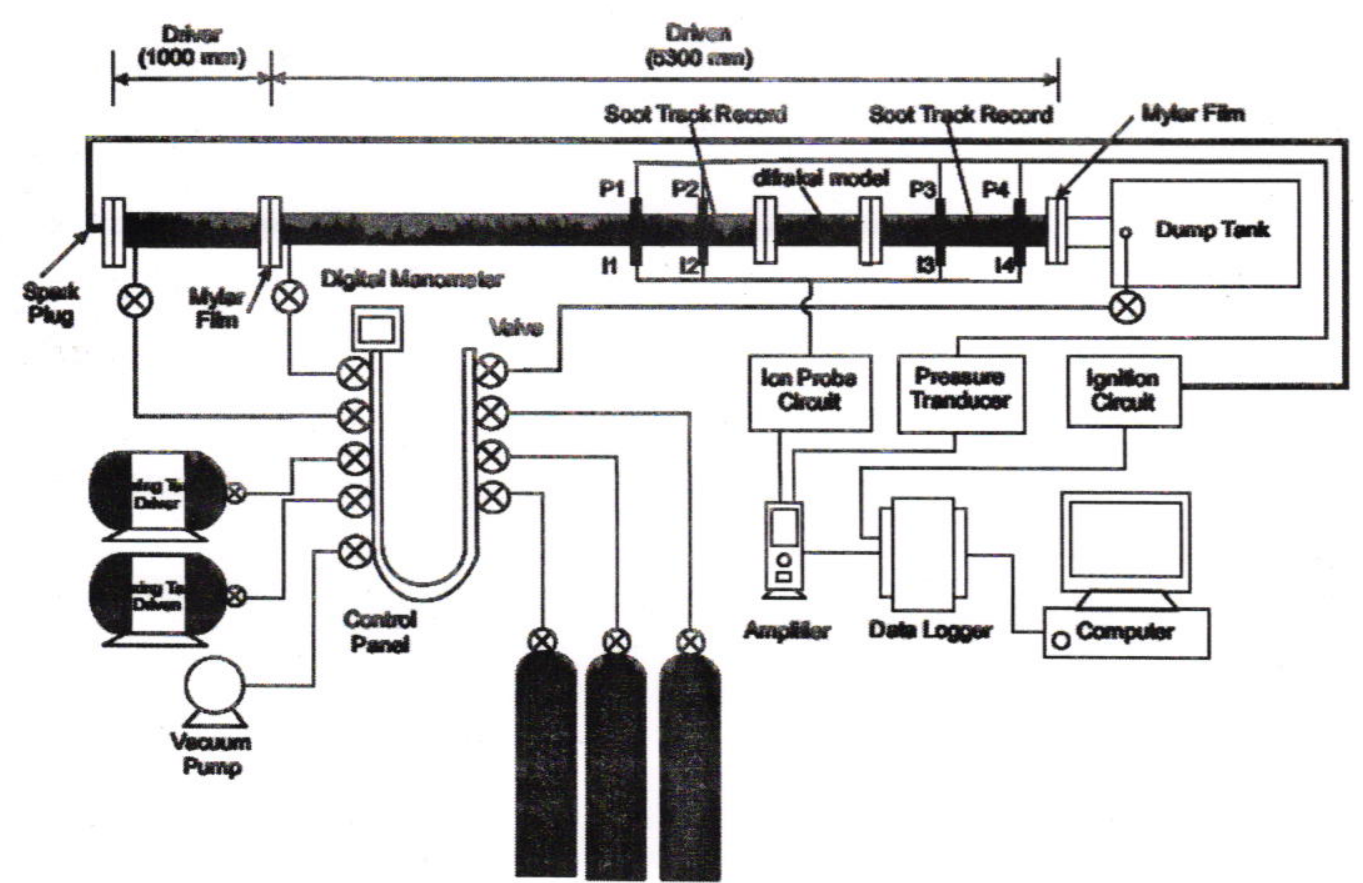

Gambar 1. Skema pipa uji detonasi horizontal, panjang total $\mathrm{L}=6300 \mathrm{~mm}$ dan diameter dalam $\emptyset=50 \mathrm{~mm}$. Model facing step $50 \%$ berada di antara P2 dan P3. Soot track record dipasang di upstream dan downstream model facing step.

\section{METODE PENELITIAN}

Pada Gambar 1 menunjukkan skematik eksperimen, timana pipa uji detonasi (PUD) dan alat-alat pendukung lainnya diinstal. PUD dengan panjang total $6.300 \mathrm{~mm}$ dan diameter dalam $50 \mathrm{~mm}$ dibagi dalam 2 bagian, yaitu bagian pertama disebut seksi driver dan bagian kedua disebut seksi driven. Seksi driver berfungsi memberikan energi inisiasi yang besar ke dalam seksi driven sehingga sebelum upstream dari model diharapkan gelombang detonasi sudah terbentuk dengan stabil. 
Gelombang detonasi akan merambat dari seksi driver melewati seksi driven yang dipasang model facing step $50 \%$ menuju ke arah dump tank.

Dalam penelitian ini, model facing step terbuat dari alumunium dengan panjang $300 \mathrm{~mm}$, diameter $50 \mathrm{~mm}$ dan disayat sebesar $50 \%$ digunakan sebagai model untuk mengetahui mekanisme dan karakteristik gelombang detonasi serta efek dari variasi tekanan terhadap perambatan detonation.

Empat sensor dipasang sepanjang seksi driven dimana masing-masing 2 sensor tekanan dipasang di daerah upstream $\left(\mathrm{P}_{1}\right.$ dan $\left.\mathrm{P}_{2}\right)$ dan downstream $\left(\mathrm{P}_{3}\right.$ dan $\left.\mathrm{P}_{4}\right)$ dari model facing step.

Tabel 1. Experimental conditions

\begin{tabular}{|c|c|c|}
\hline Parameter & Driver tube & Driven \\
\hline Fuel & $\begin{array}{c}\text { Hydrogen } \\
\left(\mathrm{H}_{2}\right)\end{array}$ & Hydrogen $\left(\mathrm{H}_{2}\right)$ \\
\hline Oxidizer & Oxygen $\left(\mathrm{O}_{2}\right)$ & Oxygen $\left(\mathrm{O}_{2}\right)$ \\
\hline Diluent & - & Argon $(\mathrm{Ar})$ \\
\hline $\begin{array}{c}\text { Equivalence } \\
\text { ratio, } \phi\end{array}$ & 1 & 1 \\
& $\begin{array}{c}\text { stoichiometri } \\
c\end{array}$ & $($ stoichiometric) \\
\hline $\begin{array}{c}\text { Initial } \\
\text { pressure } \\
(\mathrm{kPa})\end{array}$ & 100 & $20,30,40$, \\
\hline Temperature & Room temp & $\begin{array}{c}\text { Room temp } \\
90,70,80,\end{array}$ \\
\hline
\end{tabular}

Hal ini diperlukan karena untuk mendapatkan profile tekanan shock wave di daerah upstream dan downstream dari model facing step. Untuk mendeteksi proses pembakaran pada suatu posisi, empat ionization probe juga dipasang pada seksi driven yang posisinya berhadapan dengan posisi sensor tekanan dan dipasang pada posisi $I_{1}, I_{2}, I_{3}$ dan $I_{4}$. Dengan menggunakan sensor-sensor di atas, kecepatan rata-rata dari shock wave dan reaction wave akan dapat dihitung dengan tepat. Sensor tekanan dan ionization probe tersebut dihubungkan dengan amplifier dan digital data recorder, untuk kemudian datanya dapat diolah dan divisualisasikan di komputer.

Proses pengisian campuran bahan bakar gas ke dalam PUD dikontrol dengan high-precision digital pressure sensor (KEYENCE) sehingga didapatkan keakuratan tekanan awal campuran bahan bakar gas di dalam PUD.
Busi dan unit coil dari kendaraan bermotor digunakan sebagai sumber energi untuk mengawali proses pembakaran di dalam seksi driver. Proses pembakaran di daerah upstream dan downstream direkam dengan teknik soot track record untuk mendapatkan gambaran sel detonasi di sekitar model facing step, sehingga mekanisme dari perambatan detonasi dan quenching detonastdapat dipahami.

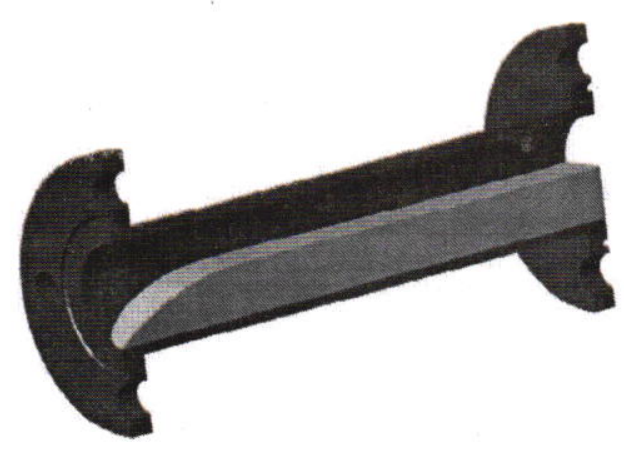

Gambar 2. Model facing step $50 \%$

Campuran bahan bakar yang digunakan dalam penelitian ini adalah gas hidrogen dengan oxidizer oksigen pada kondisi stoikiometrik. Campuran bahan bakar yang digunakan dalam penelitian ini adalah gas hidrogen dengan oxidizer oksigen pada kondisi stoikiometrik.

Campuran bahan bakar tersebut disimpan selama minimal 12 jam sebelum digunakan dalam eksperimen untuk menjamin homogenitas yang lebih lebih baik. Tekanan awal campuran bahan bakar di dalam PUD disetting pada tekanan $10 \mathrm{kPa}$ sampai $100 \mathrm{kPa}$ dan dilakukan pada suhu ruangan berkisar antara $27-33^{\circ} \mathrm{C}$ seperti dalam Tabel 1.

Dari tahapan di atas, diharapkan parameterparameter termodinamika yang mempengaruhi perambatan detonasi bisa didapatkan dan digambarkan dengan jelas. sehingga dengan mudah dapat diimplementasikan dalam proses desain detonation arrester untuk sistem berbahan bakar hidrogen.

\section{HASILPENELITIAN}

Dari hasil penelitian ini didapatkan data tekanan gelombang kejut, ionisasi api pembakaran dan sel detonasi, maka perambatan gelombang detonasi dapat diklasifikasikan menjadi tiga 
kondisi perambatan shock wave dan reaction wave setelah melalui facing step yaitu, (a) Reinisiasi detonasi oleh adanya DDT, (b) Reinisiasi detonasi oleh adanya S-W, (c) Transmisi detonasi. Masing-masing pola rambatan akan dijelaskan berikut ini.

Dari pengujian pada tekanan awal $20 \mathrm{kPa}$, gelombang detonasi merambat pada kondisi stabil pada $\mathrm{P}_{1}$ dan $\mathrm{P}_{2}$ seperti terlihat pada gambar 3a, Setelah melalui facing step, gelombang detonasi ter-difraksi menjadi gelombang deflagrasi yang disebabkan karena suddent enlargement.

Di daerah dimana sensor $P_{3}$ ditempatkan, kenaikan tekanan $\mathrm{P}_{3}$ tidak bersamaan dengan turunnya sinyal ionisasi, sehingga dapat dikatakan bahwa pada daerah ini perambatan pembakaran dikategorikan gelombang deflagrasi. Hal ini diperkuat dengan besarnya kenaikan tekanan pada sensor $\mathrm{P}_{3}$ hanya 4 kali tekanan awal $(80 \mathrm{kPa})$ dimana tekanan ini jauh lebih kecil dari tekanan teoritis $\mathrm{CJ}$ detonasi, $P_{C J}=$ $350 \mathrm{kPa}$. Gelombang deflagrasi ini cenderung menjadi lebih cepat dari posisi ke posisi dan akhirnya melalui proses DDT menjadi gelombang detonasi dengan ditandai adanya deteksi naiknya tekanan di sensor $\mathrm{P}_{4}$ bersamaan dengan turunnya sinyal ionisasi.

Bila dilihat dari soot track record pada kondisi yang sama seperti tampak pada Gambar 4a, pada daerah setelah model tidak terdapat sel relatif kecil dan berubah menjadi lebih besar detonasi tetapi pada jarak $160 \mathrm{~mm}$ dari model mulai tampak sel detonasi dengan ukuran yang dan merata. Ukuran sel detonasi yang stabil dan merata ini menunjukkan bahwa setelah proses re-inisiasi gelombang detonasi merambat pada kondisi yang stabil. Kondisi ini diklasifikasikan sebagai re-inisiasi gelombang pembakaran akibat proses DDT.

Fenomena re-inisiasi detonasi oleh interaksi gelombang kejut dengan dinding pipa ditunjukan pada Gambar 4b yang terjadi pada kondisi eksperimen pada tekanan awal $p_{o}=60$ $\mathrm{kPa}$. Dampak dari adanya model facing step menyebabkan terjadinya perlambatan pembakaran, karena gelombang detonasi terdifraksi menjadi gelombang deflagrasi yang ditandai dengan tidak terbentuknya sel detonasi setelah model facing step. Melalui interaksi gelombang kejut dengan dinding pipa, gelombang deflagrasi tereinisiasi dan berubah menjadi gelombang detonasi pada jarak sebelum sensor $\mathrm{P}_{3}$, sehingga sensor $\mathrm{P}_{3}$ dan $\mathrm{P}_{4}$ mendeteksi adanya perambatan gelombang detonasi dengan ditandai naiknya sinyal tekanan bersamaan dengan turunnya sinyal ionisasi. Hal ini diperkuat dengan terbentuknya sel detonasi yang terlihat pada Gambar 4b dengan ukuran sangat kecil mulai dari bagian sisi tepi berangsurangsur merata di seluruh permukaan dengan ukuran yang stabil. Besarnya tekanan gelombang kejut hampir konstan mencapai 14.7 kali tekanan awal yaitu $882 \mathrm{kPa}$ dimana tekanan ini sedikit lebih kecil dari tekanan teoritis CJ detonasi $P_{C J}=1092 \mathrm{kPa}$.

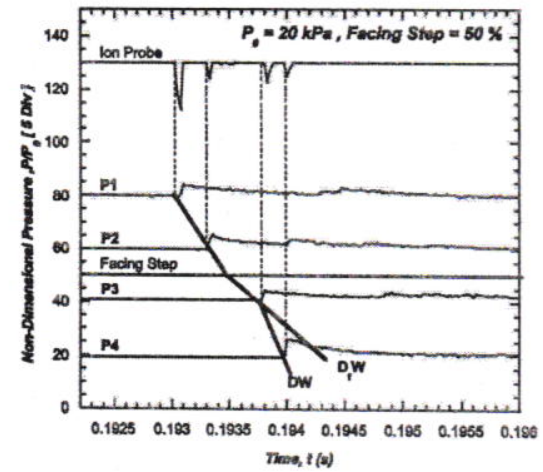

(a)

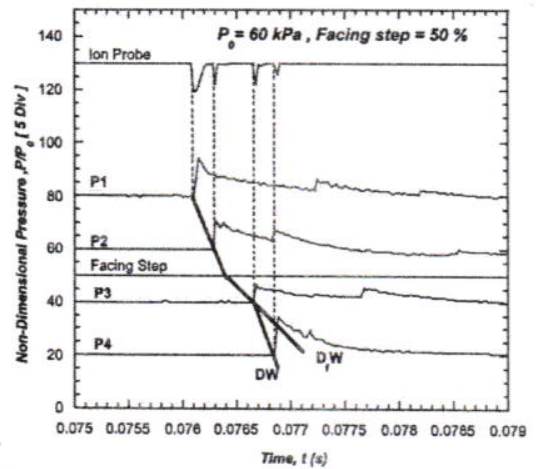

(b)

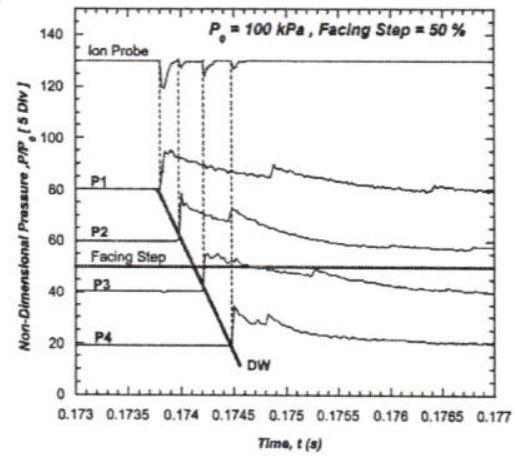

(c)

Gambar 3. Profil gelombang reaksi dan tekanan gelombang kejut pada kondisi (a) re-inisiasi katena DDT, $P_{\circ}=$ $20 \mathrm{kPa}$ (b) re-inisiasi detonasi karena $\mathrm{S}-W, P_{o}=60 \mathrm{kPa}$. (c) transmisi detonasi $P_{o}=100 \mathrm{kPa}$, 


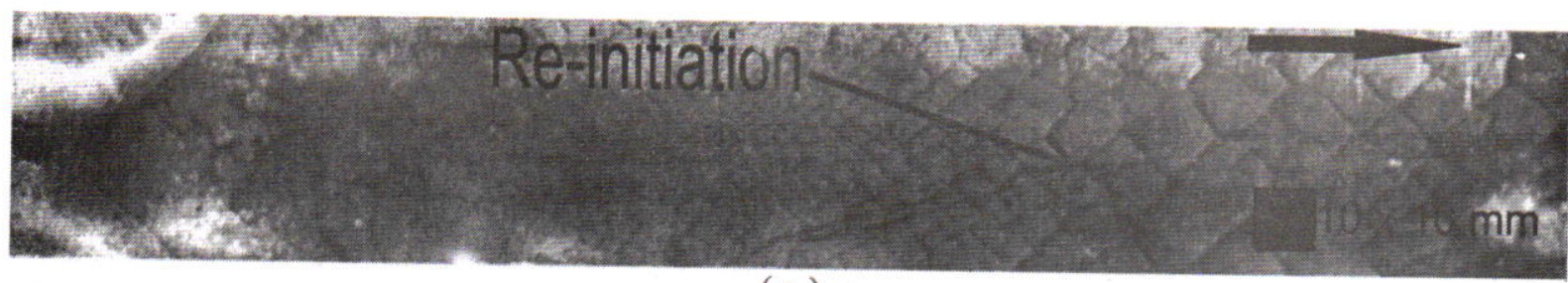

( a )

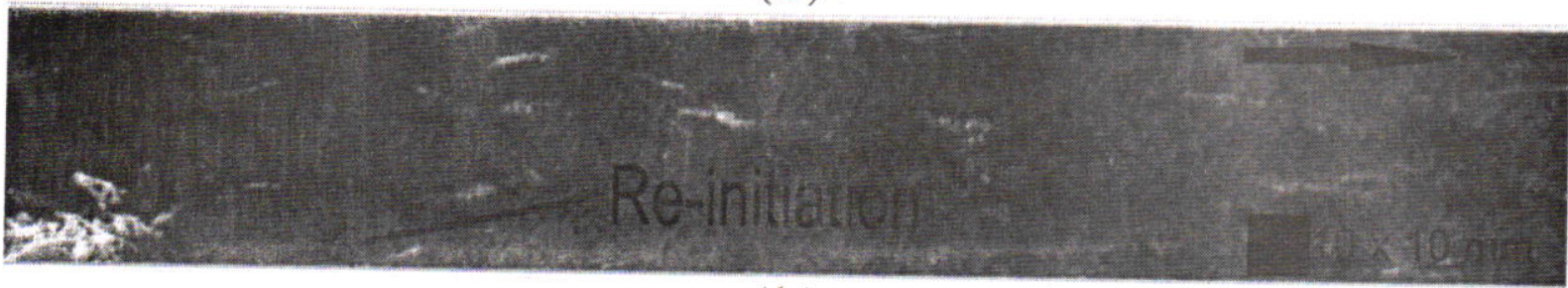

(b)

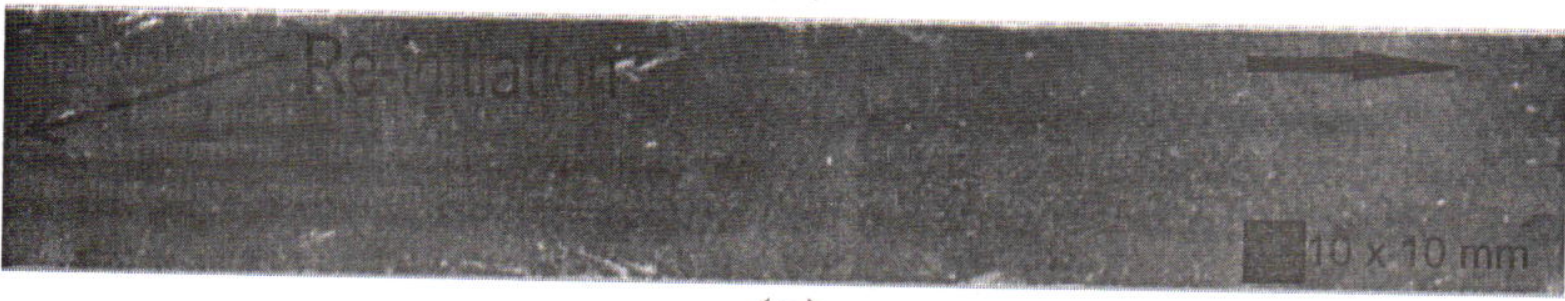

(c)

Gambar 4. Rekaman soot track record di belakang facing step pada kondisi (a) ) Reinisiasi detonasi oleh proses DDT (b) Reinisiasi detonasi oleh interaksi gelombang kejut dengan dinding pipa (c) Transmisi detonasi

Jika tekanan awal gas dinaikkan kembali menjadi $100 \mathrm{kPa}$, maka kondisi di upstream dari model adalah gelombang detonasi yang stabil seperti tampak pada gambar $3 \mathrm{c}$ dan setelah gelombang detonasi tersebut melalui model facing step gelombang pembakaran tetap merambat sebagai gelombang detonasi tanpa mengalami proses quenching seperti kasus $3 \mathrm{a}$ dan 3 b. Hal ini bisa terjadi karena gelombang detonasi merambat pada media yang lebih tinggi tekanan awalnya yang sebenarnya lebih reaktif.

Bila dilihat pada soot track record pada Gambar 3c tampak bahwa proses transmisi detonasi terjadi tanpa didahului proses quenching yang masif. Sel detonasi tampak merata di daerah downstream dari model dengan ukuran yang merata dan stabil tanpa adanya daerah tanpa sel detonasi. Tipikal gelombang pembakaran seperti ini pada umumnya terjadi pada tekanan awal campuran gas yang tinggi.

Pada Gambar 5 menunjukkan hubungan antara jarak re-inisiasi detonasi dengan tekanan awal campuran bahan bakar hidrogen dan oksigen dengan diluent argon.

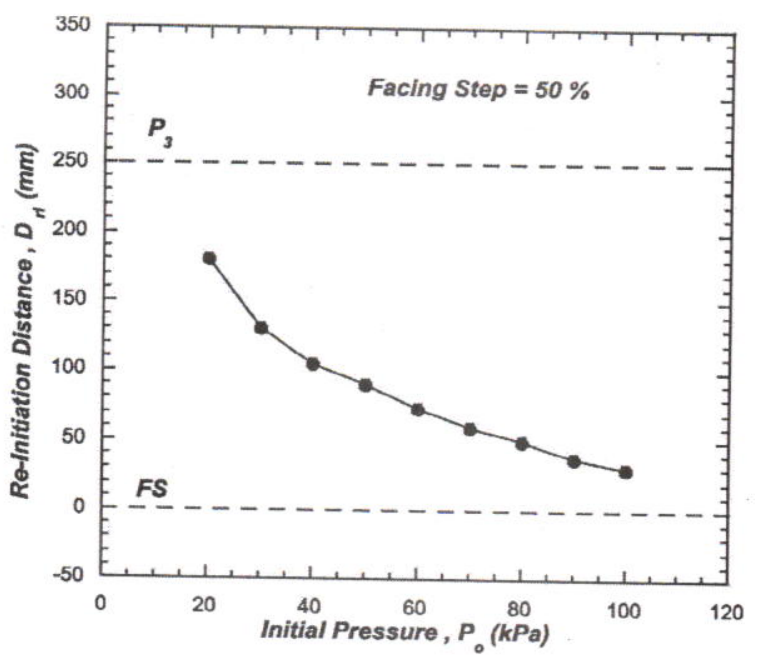

Gambar 5. Hubungan antara jarak reinisiasi detonasi Dri dengan tekanan awal campuran bahan bakar

Sumbu vertikal merupakan jarak reinisiasi detonasi Dri dan sumbu horizontal merupakan tekanan awal campuran bahan bakar hidrogen dan oksigen dengan diluent argon. Dari penelitian ini didapatkan hasil bahwa dengan tekanan yang semakin kecil maka jarak reinisiasi detonasi Dri akan lebih panjang. 


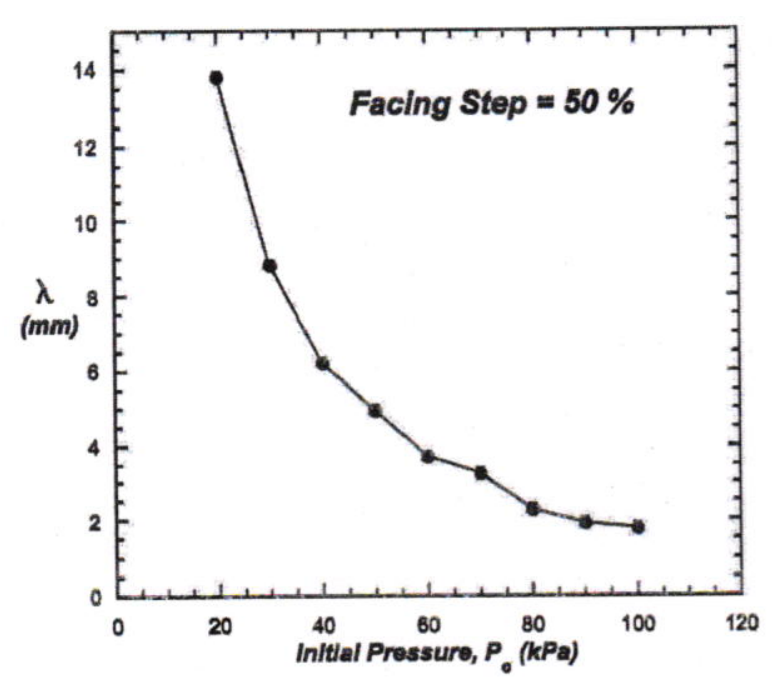

Gambar 6. Hubungan tekanan inisiasi, po terhadap lebar sel detonasi $\lambda$

Proses re-inisiasi detonasi yang disebabkan oleh adanya proses DDT terjadi pada tekanan awal 20-50 kPa, sedangkan fenomena re-inisiasi detonasi terjadi karena pengaruh interaksi gelombang kejut dengaan dinding pipa (S-W) pada tekanan awal 60-100 $\mathrm{kPa}$. Dari grafik gambar 5 tampak bahwa kondisi reinisiasi detonasi umumnya selalu terjadi sebelum posisi $\mathrm{P}_{3}$, hal ini menunjukkan bahwa proses re-inisiasi selalu terjadi pada jarak yang sangat pendek dari model bila dihitung dari model:

Dan dari grafik ini juga mendemontrasi kan bahwa re-inisiasi detonasi sangat dipengaruhi oleh tekanan awal campuran gas, semakin tekanan awal campuran gas maka semakin pendek jarak re-inisiasinya.

Gambar 5 menunjukkan hubungan antara tekanan inisiasi dengan lebar sel detonasi $\lambda$. Sumbu vertikal merupakan lebar sel detonasi $\lambda$, sedangkan sumbu mendatar merupakan tekanan inisiasi $\left(P_{o}\right)$. Dari grafik tersebut menunjukan semakin besar tekanan inisiasi maka sel detonasi semakin kecil. Hal ini mengidikasikan bahwa lebar sel detonasi $\lambda$, sangat bergantung dari tekanan inisiasi dimana semakin besar tekanan inisiasi maka lebar sel detonasi semakin kecil. Ohyagi S. et al. pada tahun 2002 melaporkan bahwa parameter detonasi tidak hanya bergantung pada tingkat kereaktifan gas mempengaruhi kekuatan dari gelombang kejut tetapi lebih pada ukuran sel detonasi.

\section{KESIMPULAN}

Tiga kondisi mekanisme perambatan gelombang pembakaran dapat diobservasi dari penelitian ini, yaitu, (a) Reinisiasi detonasi oleh adanya DDT, yaitu kondisi merambatnya kembali gelombang detonasi akibat proses deflagration to detonation transition di daerah downstream dari model setelah sebelumnya quenching detonasi akibat gelombang ekspansi, (b) Reinisiasi detonasi oleh adanya S-W, kondisi merambatnya kembali gelombang detonasi akibat adanya interaksi gelombang kejut dengan dinding pipa

c) transmisi detonasi, merupakan proses perambatan gelombang detonasi tanpa melalu proses quenching di daerah downstream dari model.

Ketiga mekanisme perambatan gelombang yang dapat diobservasi sangat dipengarui oleh tekanan awal campuran gas. Tekanan awal campuran gas yang rendah akan membuat mekanismenya adalah quenching detonasi, tekanan awal menengah mekanismenya adalah re-inisiasi, sedangkan bila tekanan awalnya tinggi akan terjadi mekanisme transmisi gelombang detonasi.

Tekanan awal campuran gas sendiri juga sangat mempengaruhi jarak re-inisiasi gelombang detonasi pada kondisi re-inisiasi detonasi akibat DDT, semakin tinggi tekanan awal, maka semakin pendek jarak re-inisiasi detonasi-nya.

\section{DAFTAR PUSTAKA}

Ohyagi S., T. Obara, S. Hoshi, P. Cai, T. Yoshihashi, 2002, "Diffraction and reinitiation of detonations behind a backward-facing step", Shock Wave, v12.

Sentanuhady J., Obara T., Tsukada Y., Ohyagi S., 2006: Re-initiation processes of detonation wave behind slit-plate:influence of initial test gas pressure. Trans. Jpn. Soc. Mech. Eng. Ser.B72, 3158-3165.

Santoso T., Sentanuhady J., 2010: Mekanisme Re-inisiasi Perambatan Gelombang Detonasi di Belakang Celah Sempit. Proocedings Seminar Nasional Thermofluid 2010. 